\title{
An In Vivo Evaluation of Some Denti- frices in Reducing Salivary Level of Mutans Streptococci and Lactobacillus
}

Summaya A Al-Hamdonii BSc, MSc (Asst Lec.)

Ali S Hassan BDS

\section{Department of Biology}

College of Sciences, University of Mosul

Ninevah Health Directorate

Ministry of Health

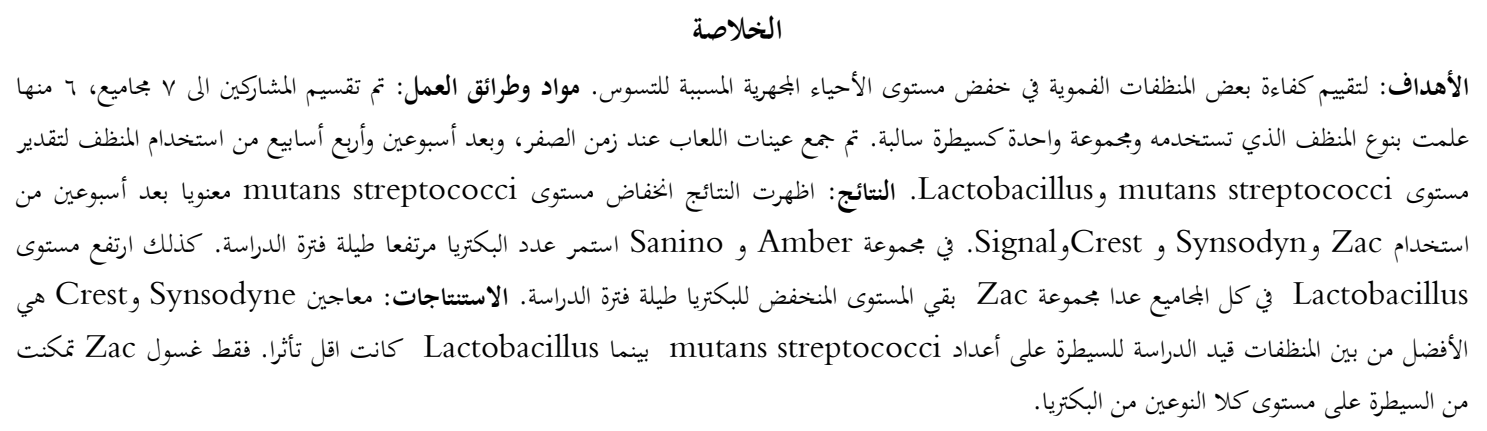

\section{ABSTRACT}

Aims: This study aimed to evaluate the efficacy of some oral dentifrices in the reduction of cariogenic organism levels. Materials and Methods: The volunteers were divided into7 groups; 6 of them labeled with the type of dentifrice they use, plus one negative control. Saliva samples were collected at the baseline, after 2 and 4 weeks of dentifrice application to estimate mutans streptococci and lactobacillus levels. Results: Mutans streptococci level significantly declined after 2 weeks of zac, synsodyne, crest and signal use. In Sanino and amber group the elevated bacterial level remained throughout experimental period. The lactobacillus number increased in all groups except in zac there was a continuous decrease throughout the study. Conclusions: Synsodyne and crest toothpastes were the most effective among the tested dentifrices used to adjunct mutans streptococci count but lactobacillus was less affected. Only zac rinses were able to control the levels of the two bacterial types.

Key words: Oral dentifrices, dental caries reduction.

Al-Hamdonii SA, Hassan AS. An In Vivo Evaluation of Some Dentifrices in Reducing Salivary Level of Mutans Streptococci and Lactobacillus. Al-Rafidain Dent J. 2013; 13(1): 81-87.

Received: 26/6/2011 Sent to Referees: 26/6/2011

Accepted for Publication: 15/9/2011

\section{INTRODUCTION}

Dental plaque is a diverse community on the tooth surface consisting of an acid producing bacterial film. Specifically, bacteria, within the plaque, are acidogenic as they produce acid when metabolizing fermentable carbohydrates. These acids diffuse into the porous subsurface enamel or dentine, dissociate to produce hydrogen ions which are readily dissolve the calcium phosphate minerals freeing calcium and phosphate into solution which diffuses out of the teeth. This process is known as demineralization and if not halted via remineralization it eventually becomes a frank cavity. ${ }^{(1-3)}$ The microbial traits strongly associated with caries incidence include the ability to sustain production of acids at low $\mathrm{pH}$ levels leading to demineralization. The ability to form and use extra-and intracellular stored polysaccharide to aid the continuous acid production; and the ability to form a water- insoluble glucan which helps the microbial accumulation in the plaque. ${ }^{(4)}$ Mutans streptococci (MS) possess all of these virulent traits which support their role as chief pathogen in dental caries and gain with lactobacillus (LB) a selective advantage over other oral bacteria. ${ }^{(4,5)}$ MS have been associated with early demineralization while LB are implicated more within lesion progression and 
cavitations and their presence increases the risk of decalcification, hence, their count is important in making up the "Risk Profile" of patient. ${ }^{(6,7)}$ The strategies of cariogenic biofilm management include plaque elimination by home care; reduction of fermentable carbohydrate and introduction of fluoride. The practice of tooth brushing twice daily (in addition to flossing) is the standard routine suggested by the American Dental Association (ADA) to effectively preserve good oral health. It is highly correlated with the level of bacteria, in that it maintains the desired balance of bacterial repopulation on tooth surface. $(1,2,8)$ The cooperative effect of brushing and use of toothpaste containing antimicrobial agents has been suggested as one possible method to improve the efficacy of mechanical tooth cleaning to offer oral health benefits. The restraining of chemical and/or physical damage of teeth or gum can be aided by the removal of hazardous dental biofilm, dental caries prevention, inhibiting microbial aggregation and slowing their multiplication and endo- toxin release, also reduce the contamination of toothbrushes. ${ }^{(9-12)}$ The efficacy of any dentifrice is directly proportional to its effect on oral microflora implicated in oral disease. The addition of new compounds should raise concerns that new clinical trials are required to allow continued validation of the products effectiveness. ${ }^{(1,13)}$ Therefore, this study was designed to evaluate the efficacy of some oral dentifrices which will be helpful for both dentists and specialists to choose the dentifrices that reduce cariogenic organism levels and give the highlights of information about some aspects that play a role in the incidence and progression or in the treatment and restriction of dental caries.

\section{MATERIALS AND METHODS}

1. Dentifrices: Six commercial dentifrices were randomly purchased from a public pharmacies in Mosul City. The composition with an active ingredient and manufacturer company with the origin are given in Table (1).

Table (1): The composition of dentifrices used in the present study as listed on packages.

\begin{tabular}{|c|c|c|c|}
\hline Dentifrice & Composition & Active ingredient & Origin \\
\hline Signal & $\begin{array}{l}\text { Calcium carbonate, water, sorbitol, hydrated } \\
\text { silica thickener, sodium lauryl sulfate, sodium } \\
\text { monofluorophosphate, sodium carboxymethyl, } \\
\text { cellulose, trisodium phosphate, sodium saccha- } \\
\text { rine, calcium glycerophosphate formaldehyde }\end{array}$ & $\begin{array}{l}\text { Fluoride } 1450 \mathrm{ppm} \text {, cal- } \\
\text { cium glycerophosphate }\end{array}$ & England \\
\hline Crest & $\begin{array}{l}\text { Polyethylene glycol, water, sorbitol, hydrated } \\
\text { silica, tetrapotassium pyrophosphate, sodium } \\
\text { lauryl sulfate, sodium fluoride, disodium pyro- } \\
\text { phosphate, xanthan gum, aroma cellulose gum, } \\
\text { carbomer (carbomyl or sodium fluoridecarbo- } \\
\text { myl), sodium saccharin, Triclosan glycerine, } \\
\text { limonene, CI77891, CI } 74160 \text {, CI } 24260\end{array}$ & $\begin{array}{l}\text { Sodium Fluoride } \\
\text { 1450ppm }\end{array}$ & Germany \\
\hline Synsodyne & Potassium nitrate, sodium fluoride & $\begin{array}{c}\text { Potassium nitrate } 5 \% \\
\text { sodium fluoride } 0.23 \% \\
\text { (1450ppm) }\end{array}$ & $\begin{array}{l}\text { United } \\
\text { kingdom }\end{array}$ \\
\hline Sanino & $\begin{array}{l}\text { Calcium carbonate, water, sorbitol, silica, Poly- } \\
\text { ethylene glycol-8, sodium lauryl sulfate, sodium } \\
\text { monofluorophosphate, cellulose gum aroma, } \\
\text { sodium saccharin, sodium propylparaben, limo- } \\
\text { nene }\end{array}$ & & Turky \\
\hline Amber & Ingredients not included & Fluoride & Iraq \\
\hline Zac & Chlorhexidine, Sodium fluoride & $\begin{array}{c}0.12 \% \text { Chlorhexidine } \\
\text { digluconate, } 0.05 \% \text { So- } \\
\text { dium fluoride }\end{array}$ & Syrian \\
\hline
\end{tabular}


2. Culture Media: Mitis Salivarious Agar (MSA) and Rogosa agar were prepared according to Diffco manual (1998) ${ }^{(14)}$ and used for the enumeration of MS and LB respectively.

3. Participants: Seventy volunteers (av. age $=17$ years) were divided into 7 groups, 6 of them were labeled with the type of dentifrice they use plus one negative control (brush with water). They were advised to brush their teeth 3 times daily after the main meal during the study period, the mean DMFT was recorded as follows:

Signal group: $\begin{array}{lllll}3 & 3 & 1 & 7 & \text {, Sanino }\end{array}$ group: $55 \quad 51$ 11, Crest group: 0 010 10, Zac group: 1225 , Amber group : $4 \quad 6 \quad 1$ 11, Synsodyne group: $5 \quad 1 \quad 0 \quad 6$, Control group: $2 \quad 4 \quad 511$.

It was ensured that all participants will not take antibiotics during study periods.

4. Samples: $0.2 \mathrm{ml}$ of saliva beneath the tongue was collected from each participant using a sterile needle-free syringe to estimate the levels of MS and LB at the baseline and after 2 and 4 weeks of a dentifrice application and labeled as period $0(\mathrm{P} 0)$, period 1 $(\mathrm{P} 1)$ and period $2(\mathrm{P} 2)$ respectively.

5. Bacterial enumeration: Obtained saliva was decimally diluted in sterile normal saline until $10^{-4}, 0.1 \mathrm{ml}$ of the last dilution was spread on MSA and Rogosa agar using sterile L-shaped glass rod. All plates were incubated in anaerobic candle jar at $37^{\circ} \mathrm{C}$ for $48 \mathrm{hr}$. and colonies were counted. The following score was followed to refer to bacterial counts:

*Mutans streptococci (MS) scoring: $0=$ very low colonies detected, $1=<$ $10^{5} \mathrm{cfu}$

$2=>10^{5}$ but $<10^{6} \mathrm{cfu}, 3=>10^{6} \mathrm{cfu}$

$*$ Lactobacillus scoring (LB): $0=$ very low colonies detected, $1=\approx 10^{3} \mathrm{cfu}$, $2=\approx 10^{4} \mathrm{cfu}, 3=\approx 10^{5} \mathrm{cfu}$.

6. Statistical analysis: the results were analyzed using Mann- Whitney test at $p$ value $\leq 0.05$.

\section{RESULTS}

An overview of the results illustrated in Figure (1) and (2) showed that in all dentifrices groups MS were more affected than LB. The level of MS was high in the control group throughout the experimental periods.

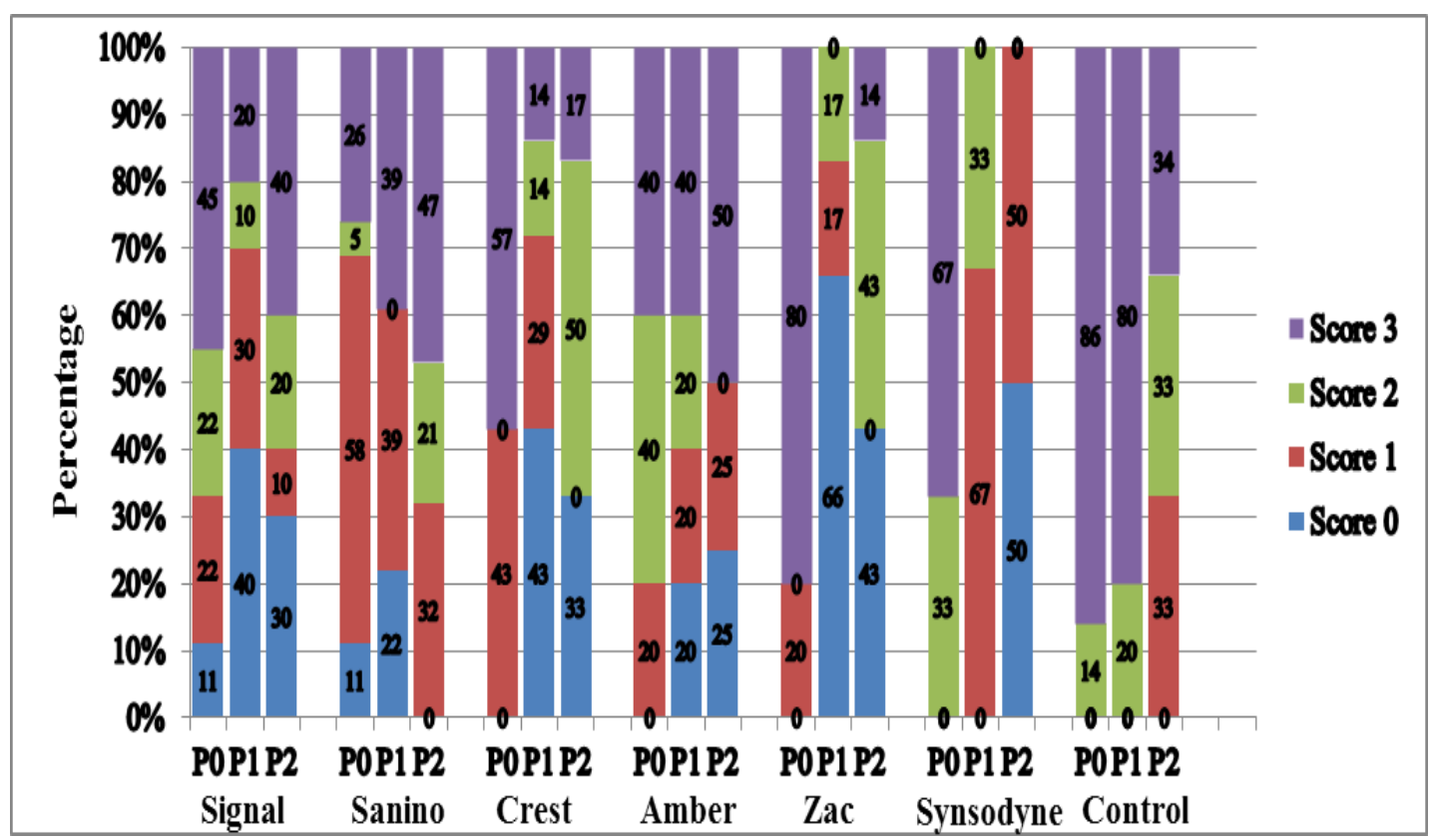

Figure (1): The percentages of mutans streptococci score during study periods. 


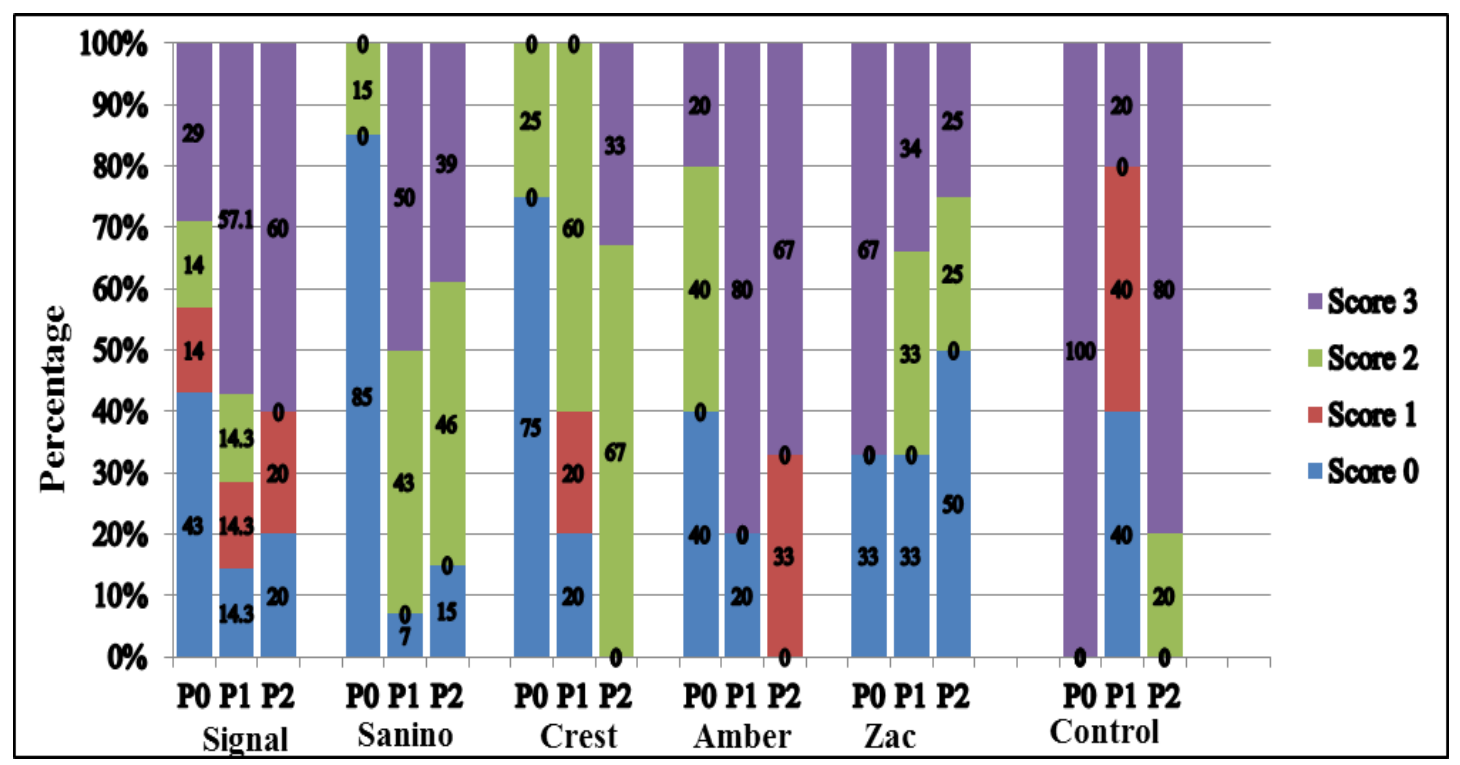

Figure (2): The percentages of lactobacillus score during study periods.

The reduction of MS level from score 3 to score 1 after 2 weeks of synsodyne use with a $p$ value of 0.04 was noted and remained limited after 4 weeks of use. Also, there was a decline in MS level from score 3 at P0 to score 0 at P1 after zac and crest use with significant differences from control group $(p=0.01,0.02$ respectively), whereas at $\mathrm{P} 2$ the bacterial count raised to score 2 but remained less than baseline with no significant differences from control group. Statistical differences were observed in the reduction of MS level in signal group after 2 weeks of use, but there was an increase after4 weeks with no significant differences from control. In contrast there was a significant increase in bacterial count in sanino group after 2 weeks and remained high even after 4 weeks of use. Also in amber group, the elevated bacterial level remained throughout the experimental period with no statistical differences from the control group.

In respect to LB levels, the differences in the bacterial level among groups were different from the fashion of MS. At P1 the LB number decreased only in zac group while increasing in all groups. Significance was evident only in sanino group. At P2 the elevated LB level remained in signal, crest and amber group, while in sanino group it decreased from that of P1 but still higher than P0. In zac group the LB level continuously decreased after 4 weeks of use with no significant variations between any group with the control. Table(2) expresses the action of the dentifrices ingredients used in this study.

Table (2): The action of dentifrices ingredients.

\begin{tabular}{ll}
\hline \multicolumn{1}{c}{ Component } & \multicolumn{1}{c}{ Action } \\
\hline Calcium carbonate, Calcium pyrophosphate, Silica & Abrasive agents \\
Carboxy methyl cellulose, Hydroxy methyl cellulose, & Gelling or binding agents \\
\multicolumn{1}{c}{ Silica thickeners, Xanthan gum } & \\
Sodium lauryl sulfate(SLS) & Surfactant \\
Glycerol, water, Polyoxy ethyl glycolester & Humectants \\
Formaldehyde & Preservative \\
Sodium saccharin, Sorbitol & Sweeteners \\
Sodium fluoride, Sodium fluorophosphates & Provide ionic fluoride \\
Chlorhexidine, Triclosan, Limonene & Antimicrobial agents \\
Potassium nitrate & Nerve fiber transmission blocking \\
\hline
\end{tabular}

(Stamm, 2007; Davies et al., 2010). 


\section{DISCUSSION}

Saliva sample was collected for bacterial count, because it represents the microbial oral load and their average colonization in the dentition. On the other hand, plaque samples represent only single site and there is a wide variation in bacterial numbers among different tooth surfaces, as well as the collection of plaque mass is difficult, time consuming and one can easily miss a key area when collecting the sample. Therefore, literature supported the reliability of using saliva as a referent value in epidemiological studies for giving better data than dental plaque. ${ }^{(15,16)}$

Because oral cavity infections are significant in individual's health, modern toothpastes and mouthrinses were invented to aid in the removal of foreign particles and food substances, cleaning the tooth and routine control of bacterial plaque. Thus ingredients possessing antimicrobial activity are included in several toothpastes. ${ }^{(8,17,18)}$

According to the listed data, we conclude that synsodyne and crest toothpastes, and zac rinses are the best dentifrices used to adjunct MS count as they can keep its level lower than the baseline; while the overview of the products' effect on LB indicate that this microorganism is less affected as its count remained high. Therefore, the dentifrice does not necessarily have the same effect upon the two bacterial types, except zac rinses where LB count decreased in P1 and more decreased at $\mathrm{P} 2$.

Several researches have reported that the application of dentifrices will be effective against cariogenic oral microflora especially MS but the effect on LB is confused. Lima and others ${ }^{(19)}$ recorded a significant reduction in MS level in CHX and $\mathrm{NaF}$ plus $\mathrm{CHX}$ groups, but considering all groups with related to $\mathrm{LB}$, there was no significant reduction probably because it was hidden in habitats not affected by these products as they observed among irradiated patients. In vivo study ${ }^{(6)}$ showed that long- term use of fluoride affect the salivary level of MS but not of LB and supposed that LB might have a good resistance to fluoride.

CHX is the most successful antibacte- rial therapy against supragingival and subgingival bacterial communities; daily use of this agent for two weeks can markedly reduce the cariogenic bacteria in mouth and prevent its recolonization for 3-6 months, so it may be employed as adjunct in patients with high caries activity and high count of MS. ${ }^{(2,7)}$

The most common effective agents recommended by WHO, ADA and FDI are fluoride and triclosan, and regular evaluation of the efficacy of fluoridated toothpastes by the private laboratory has been recommended by WHO. ${ }^{(12)}$ Various fluoride forms such as amine fluoride, sodium fluoride, and sodium monofluorophosphate have been used in toothpaste formulations. A systemic review concluded that they were equally preventing caries and the effect is concentration dependent. ${ }^{(10)}$ Fluoride can prevent and arrest caries by inhibiting demineralization and enhancing remineralization by forming a low solubility veneer and inhibiting bacterial metabolism after diffusing into the bacteria as hydrogen fluoride. ${ }^{(2)}$

Leyster et al., ${ }^{(8)}$ failed to support the hypothesis that fluoride is an essential ingredient in an antimicrobial dentifrices as the non fluoridated and two of the fluoridated toothpastes had the largest average inhibition zone with no statistical differences. This agrees with our results as we found that toothpastes having just fluoride as the sole active ingredient had less effect than crest toothpaste which contain, in addition to, triclosan, SLS and limonene as an antibacterial agent. This was also proved by a previous in vitro study. ${ }^{(12)}$ Other in vivo studies ${ }^{(20)}$ on several toothpaste brands containing triclosan, fluoride and herbal components outlined conclusions that some toothpastes significantly increase bacterial saliva count; a toothpaste containing the two antimicrobials $\mathrm{NaF}$ and triclosan had more reduction in oral microflora than non triclosan- containing toothpastes or with $\mathrm{NaF}$ alone.

Triclosan is incorporated into fluoridated dentifrices to enhance the anticaries potential of fluoride in reducing supragingival plaque. ${ }^{(3)}$ It inhibits the growth of a wide range of microorganisms and prevents acid production, there- 
by provides preventive effect on the enamel demineralization. ${ }^{(13,21)}$ Owing to its lipophilic nature, it is absorbed to the lipid portion of the bacterial cell membrane, then inhibiting the enzyme enoylacyl carrier protein reductase blocking lipid biosynthesis and leading to growth inhibition or cell lysis. ${ }^{(21,22)}$

Crest toothpaste also contains sodium lauryl sulfate, an anionic detergent, possessing considerable antimicrobial properties that reduce plaque growth. ${ }^{(23)}$ Also contains limonene, a component of Melaleuca alternifolia (Tea Tree Oil), which is a popular natural topical antiseptic included in toothpastes as an antimicrobial agent to help in reducing plaque regrowth or plaque organisms vitality, preventing MS adhesion, gingivitis and halitosis. ${ }^{(24)}$

Potassium based toothpastes provide measurable sensitivity reduction through two weeks of twice daily use. Potassium nitrate is considered a superior desensitizer of nerve fibers in the dentinal tubules since it provides potassium ion which blocks neutral transmission for up to four weeks. Its mechanism of action hovers on oxidizing effect or blocking tubules by crystallization, it also reduces dentinal sensory nerve due to its depolarizing activity. ${ }^{(10,25,26)}$

In the present investigation, the most beneficial advantage of the toothpaste use was in a group having the lowest decayed teeth (crest and zac), while in the groups with more decayed teeth and largest DMFT (sanino and amber) the benefits was less as they suffer from highly elevated cariogenic activity than crest and zac group. This fact gives an additional explanation for why crest and zac group displayed more response to the anticariogenic effect of their dentifrices. Even though, the decayed teeth were more than the filled teeth in synsodyne group, this toothpaste displayed relatively high effectiveness in controlling the MS level, so we considered it the most useful one.

In addition to the antimicrobial agents included in oral dentifrices, diet composition and fermentable carbohydrates and practice of sound oral care ultimately play an important role in factors contributing to oral disease ${ }^{(8)}$,but despite these counsels and improved dental care, dental caries remains a pandemic condition, hence the adjunctive therapies are necessary and even greater research must be done on the products ${ }^{(2)}$ Finally, the inheritance effect, psychological upset and stress hormones, all these factors remain the main adjunct for teeth and oral health. Also, person perseverance on constancy brushing just when he/she has a toothache or during the period of treatment and visiting the dentist.

\section{REFERENCES}

1. Wolff M, Larson C. The cariogenic dental biofilm: good, bad or just something to control? Braz Oral Res. 2009; 23:31-38.

2. Featherston J.The science and practice of caries prevention. J Am Dent Ass. 2000; 131:887-899.

3. Garcia-Godoy F, Hicks M . Maintaining the integrity of the enamel surface: the role of dentinal biofilm saliva and preventive agents in demineralization and remineralization. J Am Dent Ass. 2008; 139: 25s-34s.

4. Jeevarathan J, Deept A, Muthu M, Rathna P, Chamundeeswri G. Effect of fluoride varnish on Streptococcus mutans count in plaque of caries- free children using dentocult SM strip mutans test: A randomized controlled triple blind study. J India Soc Pedod. Prevent. Dent. 2007;25:157-163

5. Featherstone J. The caries balance: contributing factors and early detection. J California Dent. Assoc. 2003; 31(2):129-133

6. Yoshihara A, Sakuma S, Kobayshi S, Miyazaki H. Antimicrobial effect of fluoride mouthrins on mutans streptococci and Lactobacilli in saliva. American Academy of Pediatric Dentistry. 2001; 23(2): 113-117.

7. Basaran G, Hamame O, Basaran E, What kind of orthodontic treatment can affect the Lactobacilli and Streptococcus mutans level? Biotechnol. \& Biotechnol. Eq.2006;20(1): 144-148.

8. Leyster C. An investigation of the level of antimicrobial efficacy in commercial dentifrices on Streptococcus mutans and Lactobacillus. Saint Martin's University. Biology J. 2006; 1:155-165. 
9. Steinberg D, Mor C, Dogan H, Kaufmann D, Rotstein I. Formation of Streptococcus mutans biofilm followingtoothbrushing with regular and whitening toothpastes. A.J.Dent.2003; 16(1): 58-60.

10.Davies R, Scully C, Preston A. Dentifrices-an update. Med Oral Patol. 2010; 131: 887-899.

11.Shahabi S, Pesaran F, Kharazifard M. Abrasive properties of three different toothpastes. J Dent. 2008; 5(1): 7-11.

12.Sadeghi M, Assar S. An in vitro antimicrobial activity of ten Iranian- made toothpastes. Dent Res J. 2009; 6(2): 87-92.

13. Vyas Y, Chandrashekra K, Batnagar M, Sharma K. Effect of Spilanthes calva DC. Rooy, herbal extract \&synthetic dentifrices on oral microflora using in vitro human tooth model. J. of herbal medicine \& toxicology, original article,2009; 3(1): 141-148.

14.Difco Manual of Dehydrated Culture Media and Reagents for Microbiological and Clinical Laboratory Procedures. 9thed. ,Difco Laboratories Inc. , Detroit, Michigan, USA.(1998).

15.Almas K, Al-Zeid Z.The immediate antimicrobial effect of a toothbrush and miswak on cariogenic bacteria: A clinical study. J. Contemporary Dent Practice.2004; 5(1): 1-9.

16.Jurič H., Šhrinjarič I, Boŝnjak A. Effectiveness of different preventive procedures in the control of some caries risk factors. Acta Stomato Croat.2007; 41(1):39-48.

17. Ogunshe A, Odumesi O. Users' perception and efficacy of indigenous adjunct teeth- cleaning agents on the bacterial flora of human dental caries. African J. clin. experiment.Microbial.2010;11(3): 182-193.

18. McBain L, Ledder R, Sreenivasan P, Gilbert P. Selection for high level re- sistance by chronic triclosan exposure is mot universal. J.A.C.2004; 53:772777.

19.Lima K, Neves A, Beyruth J, Magalahăes F, Uzeda M. The levels of infection and colonization of some oral bacteria after use of sodium fluoride, chlorhexidine and a combined chlorhexidine with sodium fluoride muothenses. B. J. microbial.2001; 32:158-161.

20.OkpalngoJ, Ibrahim K, Inyang U. Toothpaste formulation efficacy in reducing oral flora. Trap.J.Pharm.2009; 8(1): 71-77.

21.Saunders K, Greenam J, Mckenzie C. Ecological effect of triclosan and triclosan monophosphate on defined mixed cultures of oral species grown in continuous culture. J.A.C.2000; 45:447-452.

22.McBain A, Bartolo R, Catrenich C, Charbonnean D, Ledder R, Gilbert P. Effect of ticlosan- containing rinse on the dynamics and antimicrobial susceptibility of in vitro plaque ecosystem.J. Antimicrobial agents and chemotherapy.2003; 47(11): 35313538.

23.Karlisey R, Mackey A, Stookey G. In vitro remineralization efficacy of sodium fluoride system containing unique forms of calcium.Am. J. Dent. 2009; 22(3); 185-188.

24.Hammar K, Dry L, Johnson M, Michalak E, Carrson C, Riley T. Susceptibility of oral bacteria to Melaleuca alternifolia (tea tree) oil in vitro. Oral Microbiol. Immunol.2003; 18: 389-392.

25.Stamm J. Multi-function toothpastes for better oral health: a behavioral perspective. I.D.J. 2007; 57: 1-13.

26.Bartold P.Dental hypersensitivity: a review. Australian Dental J. 2006; 51(3):212-218. 